\title{
Condensation of the air-steam mixture in a vertical tube condenser
}

\author{
Jan Havlík ${ }^{1, a}$, Tomáš Dlouhý ${ }^{1}$ \\ ${ }^{1}$ Czech Technical University in Prague, Faculty of Mechanical Engineering, Department of Energy Engineering, Technická 4, \\ 16607 Prague 6, Czech Republic
}

\begin{abstract}
This paper deals with the condensation of water vapour in the presence of non-condensable air. Experimental and theoretical solutions of this problem are presented here. A heat exchanger for the condensation of industrial waste steam containing infiltrated air was designed. The condenser consists of a bundle of vertical tubes in which the steam condenses as it flows downwards with cooling water flowing outside the tubes in the opposite direction. Experiments with pure steam and with mixtures of steam with added air were carried out to find the dependence of the condensation heat transfer coefficient (HTC) on the air concentration in the steam mixture. The experimental results were compared with the theoretical formulas describing the cases. The theoretical determination of the HTC is based on the Nusselt model of steam condensation on a vertical wall, where the analogy of heat and mass transfer is used to take into account the behaviour of air in a steam mixture during the condensation process. The resulting dependencies obtained from the experiments and obtained from the theoretical model have similar results. The significant decrease in the condensation HTC, which begins at very low air concentrations in a steam mixture, was confirmed.
\end{abstract}

\section{Introduction}

Waste steam produced in many industrial processes has typically low parameters and it may contain infiltrated air limiting its following utilization. Therefore the steam is often exhausted to the ambient atmosphere. This paper deals with the influence of non-condensable gases (air) in a steam mixture on the utilization of its condensation heat. An evaluation of this effect is based on experiments with a condenser designed for the utilization of atmospheric pressure steam with a small content of infiltrated air. The dependence of the condensation heat transfer coefficient (HTC) on the air concentration in a steam mixture is given. The results are compared with the results of the theoretical calculation of this case. The influence of non-condensable gas on heat transfer is an important factor for the design of waste vapour heat condensers whose use may increase the energy efficiency of processes producing waste steam [1], [2].

\section{Vertical tube condenser}

Experiments are carried out on a vertical shell-and-tube heat exchanger in which the condensing water vapour flows downwards inside vertical tubes and the cooling water flows in a counter current in the outer shell (see Figure 1). This condenser design is used due to the potential presence of small solid particles in industrial waste steam (e.g. waste steam from fuel drying). These particles, which can stick to the tube wall, are spontaneously carried away from the tubes by the condensate blowing out. The condenser outlet on the vapour side is opened, so the steam condensation pressure is close to the atmospheric pressure. The tube bundle is formed by 49 tubes $865 \mathrm{~mm}$ in length, $28 \mathrm{~mm}$ in external diameter and $24 \mathrm{~mm}$ in internal diameter. The tubes are arranged in staggered arrays with a triangular tube pitch of $35 \mathrm{~mm}$. The cross-section of the shell is rectangular in shape, $223 \mathrm{~mm}$ by $270 \mathrm{~mm}$ in size. Seven segmental baffles $(223 \times 230 \mathrm{~mm})$ are used in the shell section. The tubes are made from stainless steel 1.4301 (AISI 304).
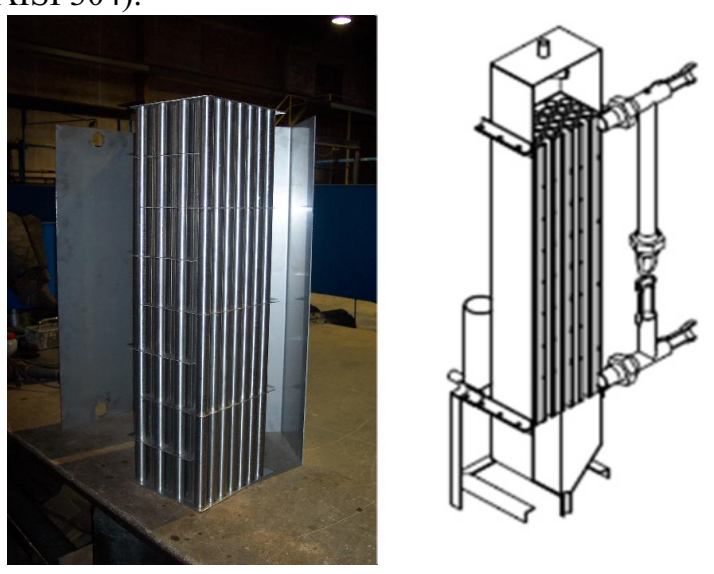

Figure 1. Vertical tube condenser

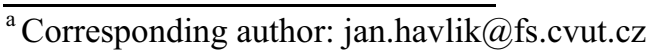




\section{Experimental set-up}

The testing loop is shown in Figure 2. Steam is produced in a steam generator. Before the steam enters the vertical tube condenser, its parameters are reduced to the required value. Measured air flow is mixed to the steam through a controllable air fan. Recirculation of the hot water enables the cooling water temperature and the cooling water flow rate in the condenser to be regulated The measured parameters needed for the determination of the HTC from the heat balance are the inlet cooling water temperature $T_{w 1}$, the temperature of water after recirculation $T_{w 2}$, the outlet cooling water temperature $T_{w 3}$, the cooling water flow rate $Q_{w}$, the volume of air added to the steam before the condenser $V_{a}$, the inlet steam pressure $p_{s}$, the inlet steam temperature $T_{S}$ and the amount of steam condensate $M_{c}$.

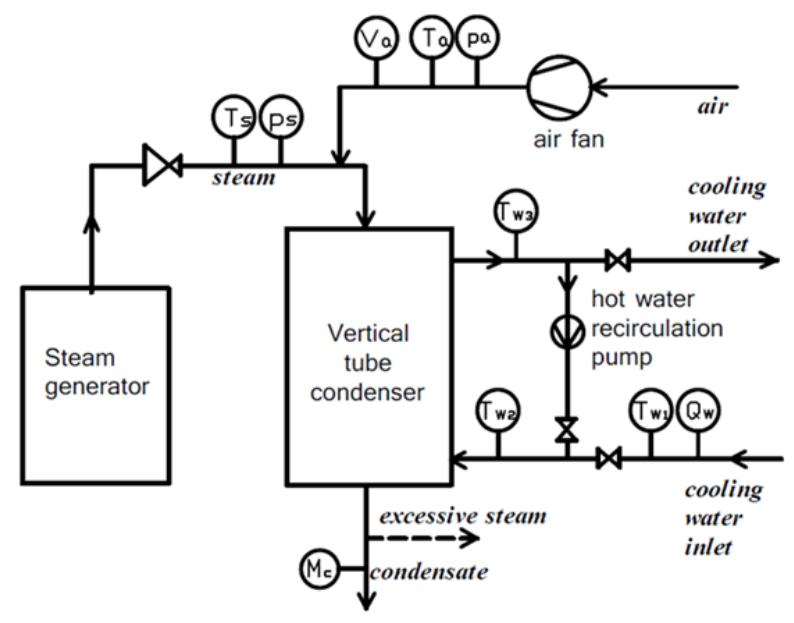

Figure 2. A schemata of the testing loop

\section{Determination of the condensation HTC}

Calculation of the HTC is based on the heat balance of the condenser [1]. The total heat power $Q$ is given by the equation

$$
Q=M_{w} \cdot c_{w} \cdot\left(T_{w, o u t}-\mathrm{T}_{w, i n}\right)
$$

where $M_{w}$ is the cooling water flow, $c_{w}$ is the specific heat capacity of water, $T_{w, o u t}$ is the outlet cooling water temperature, and $T_{w, i n}$ is the inlet cooling water temperature. The total heat power is also given by the equation

$$
Q=U \cdot A \cdot \Delta T_{l o g}
$$

where $U$ is the overall HTC, $A$ is the heat transfer surface and $\Delta T_{\log }$ is the logarithmic mean temperature difference. The tube-side HTC (vapour condensation) $h_{c}$, respectively the shell-side $\mathrm{HTC}$ (water) $h_{w}$, is possible to calculate from the term

$$
U=\frac{1 / D_{o}}{\frac{1}{d_{i} \cdot h_{c}}+\frac{1}{2 k} \ln \left(\frac{D_{o}}{d_{i}}\right)+\frac{1}{D_{o} \cdot h_{w}}},
$$

where $d_{i}$ is the inside diameter of the tubes, $k$ is the thermal conductivity of the tubes, and $D_{o}$ is the outside diameter of the tubes.

\subsection{Determination of the shell-side HTC}

For the calculation of the condensation $\mathrm{HTC} h_{c}$, it is necessary to fix the water $\mathrm{HTC} h_{w}$ for specific configuration of the heat exchanger. In the case of pure steam condensation, it is possible to calculate the condensation HTC $h_{c}$ according to the Nusselt model of pure steam condensation on the vertical wall at distance $x$ of the wall length [2], [3]

$$
h_{c}(x)=\left[\frac{\rho_{L} g\left(\rho_{L}-\rho_{p}\right) h_{f g}^{\prime} k_{L}^{3}}{4 \mu_{L} \Delta T_{\text {sat }} L}\right]^{1 / 4},
$$

where $\rho_{L}$ is the density of the condensate, $\rho_{p}$ is the density of water vapor, $h_{f g}^{\prime}$ is the latent heat of condensation, $k_{L}$ is the thermal conductivity of condensate, $\mu_{L}$ is the dynamic viscosity of condensate, $\Delta T_{\text {sat }}$ is the difference between the saturation temperature and the wall temperature, and $L$ is the wall length.

\subsection{Effect of non-condensable gas on the condensation HTC}

When the value of $h_{w}=f(\operatorname{Re}, \operatorname{Pr}) \approx f\left(M_{w}, T_{w}\right)$ [1], [3] is fixed, the value of $h_{c}$ for various steam-air mixtures is provided by Equation (3). It is necessary to maintain a constant flow of cooling water $M_{w}$ with minimal change of the water temperatures $t_{w}$, whose effect is negligible. Therefore the value of $h_{w}$ is constant during measurement. Experimental determination of the shellside HTC is described in [4].

\section{Condensation theory of mixture containing non-condensable gas}

If steam condenses in a mixture with inert gases, there is a difference in the concentrations of the steam in the bulk gas mixture $C_{\infty}$ and at the condensation phase interface $C_{i}$. Steam concentrations decrease along the length of the tube equally with corresponding steam partial pressures $p_{\infty}$ resp. $p_{i}$ and temperatures $T_{\infty}$ resp. $T_{i}$ (see Figure 3). The molecules of steam diffuse through an inert gas towards the vapour-liquid interface and mass transfer occurs [1], [3]. On the contrary in the case of pure steam condensation, the temperatures $T_{\infty}$ and $T_{i}$ are identical and constant during the process. The heat balance of the total heat transfer process is shown in Figure 3. 


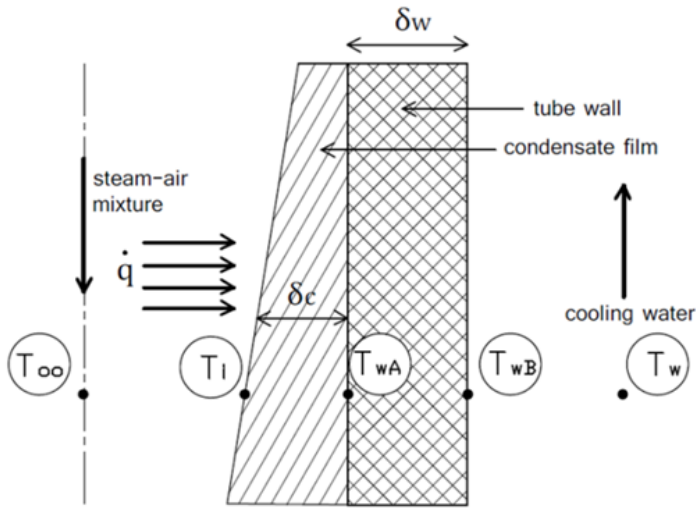

Figure 3. Heat transfer in a condenser tube

In the total heat transfer process, the value of heat flux $\dot{q}$ is constant.

- heat flux from condensing steam

$$
\dot{q}=\dot{m}_{c} \cdot h_{f g}^{\prime}
$$

where $\dot{m}_{c}\left[\mathrm{~kg} / \mathrm{sm}^{2}\right]$ is the amount of condensing steam, and $h_{f g}^{\prime}$ is the latent heat of condensation.

- heat flux through condensate film

$$
\dot{q}=h_{c i} \cdot\left(T_{i}-T_{w A}\right) \text {, }
$$

where $h_{c i}$ is the condensation HTC, where $T_{i}$ is the steam condensation temperature and $T_{w A}$ is the wall temperature.

- heat flux through the tube wall

$$
\dot{q}=\frac{k_{w}}{\delta_{w}} \cdot\left(T_{w A}-T_{w B}\right),
$$

where $k_{w}$ is the thermal conductivity of the tube wall, $\delta_{w}$ is the thickness of the tube, $T_{w B}$ is the tube wall temperature.

- heat flux to cooling water

$$
\dot{q}=h_{w} \cdot\left(T_{w B}-T_{w}\right),
$$

where $T_{w}$ is the cooling water temperature.

To determinate the condensation temperature at the phase interface $T_{i}$, it is necessary to take into account the mass transfer generated by the different partial pressures at the interface between the gas and the liquid phases $p_{i}$, and at bulk gas mixture $p_{\infty}$ [1], [3]. In accordance with the analogy between mass transfer and heat transfer, a criterial equation for laminar flow is used. The Nusselt number $N u$ is replaced with the Sherwood number $S h$, and the Prandtl number $P r$ with the Schmidt number $S c$.

For laminar flow in a pipe $(R e \leq 2300)$ in the entrance region for the boundary condition of a uniform heat flux, the local Sherwood number at distance $\mathrm{x}$ from the inlet is given by [1]

$$
S h_{x}=1.302(\operatorname{ReSc} \mathrm{D} / x)^{1 / 3} .
$$

The length of the entry region $L_{e r}$ is defined as

$$
L_{e r}=0.05 R e P r \text {. }
$$

For fully developed laminar flow in a pipe, the local Sherwood number $S h_{x}$ is constant and has the value of 4.36. The mass transfer coefficient $\beta$ is given by equation [1]

$$
\beta=\frac{S h \cdot D_{12}}{D},
$$

where $D_{12}$ is the diffusive coefficient of water vapour to air. The molar concentration at the phase interface $y_{10}$ is calculated from Equation (12) derived from the Fick law for calculation of the molar flux of condensing steam $\dot{n}_{1}$ [1].

$$
\dot{n}_{1}=\beta C_{T} \ln \left[\frac{1-y_{1 \delta}}{1-y_{10}}\right],
$$

where $C_{T}$ is the total molar concentration, $y_{1 \delta}$ is the molar concentration of steam at the boundary layer. The temperature at the phase interface $T_{i}$ and the partial pressure of steam at the phase interface $p_{i}$ are calculated from Equations (13) and (14), where $p_{t o t}$ is the total pressure in the bulk gas mixture.

$$
\begin{aligned}
p_{i} & =y_{10} \cdot p_{\text {tot }} . \\
T_{i} & =T_{\text {sat }}\left(p_{i}\right) .
\end{aligned}
$$

The $\mathrm{HTC} h_{c i}$ is given by Equation (4). The condensation HTC of the total process $h_{c}$ is usually related to the temperature difference between the bulk gas mixture temperature $T_{\infty}$ and the wall temperature $T_{w A}[1]$ according to the term

$$
h_{c}=h_{c i} \frac{\left(T_{i}-T_{w A}\right)}{\left(T_{\infty}-T_{w A}\right)} .
$$

\section{Results}

Experiments were carried out for the laminar flow of the steam mixture with an inlet tube velocity of $1.5 \mathrm{~m} \mathrm{~s}^{-1}$ which corresponds with the Reynolds number of 1700 . The range of tested mass concentration of air in the steam mixture was from 0 to 0.06 . The cooling water flow rate and inlet temperature in the exterior shell-side was fixed for all cases. The values of the condensation HTC are evaluated according to the procedure described in Chapter 4. The shell-side HTC was fixed at the value of $1550 \mathrm{~W} \mathrm{~m}^{-2} \mathrm{~K}^{-1}$. Experimental results are shown in Figure 4.

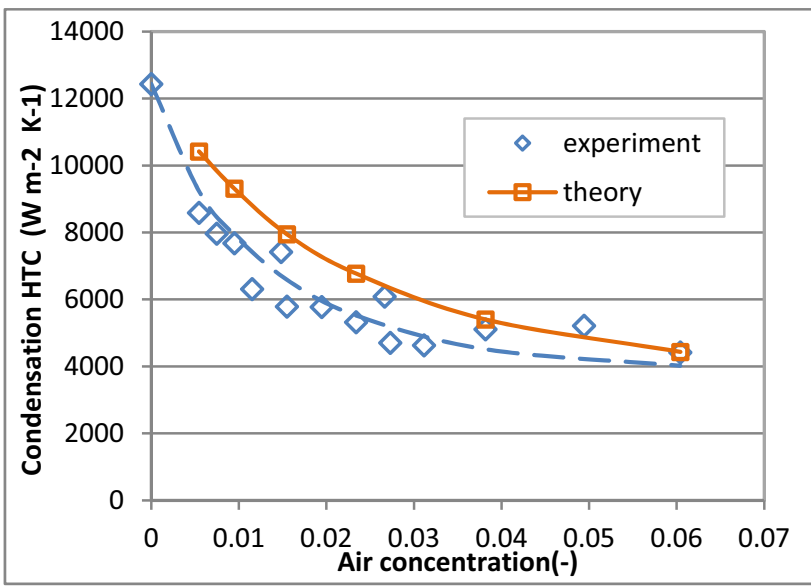

Figure 4. Effect of air content on the condensation process

The values obtained from the theoretical model are slightly higher. The deviation of the condensation HTC calculated using the theoretical formulas and evaluated by measurement ranges from $4 \%$ to $9 \%$ in the dependence on operating parameters. A significant decrease in the condensation HTC begins in both cases at very low air concentrations in the steam mixture. The 
values of condensation HTC (see Figure 4) are significantly higher in comparison with the value of the shell-side HTC. Therefore the effect of any potential inaccuracy of the HTC determination on the values of the overall HTC is relatively low for this design of a waste vapour condenser (see Figure 5).

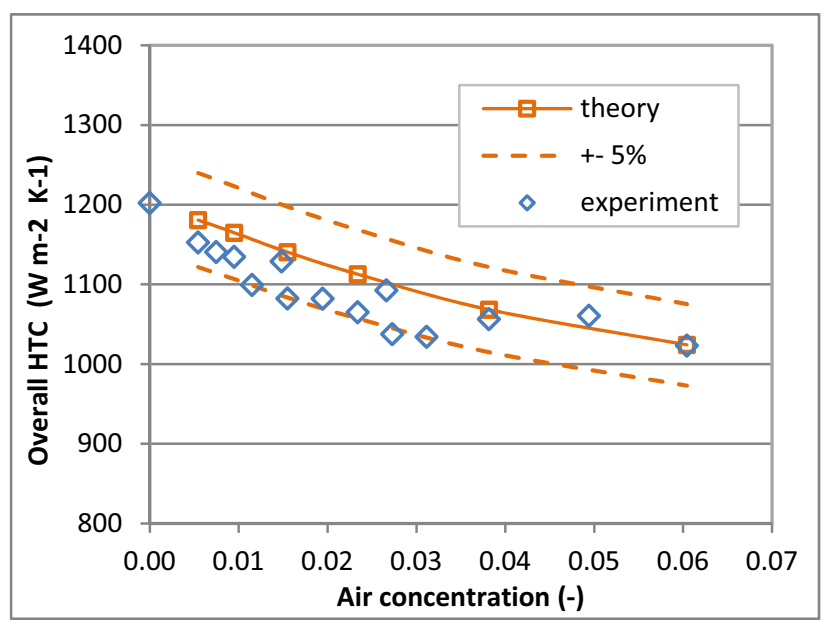

Figure 5. The deviation in the overall HTC

\section{Conclusion}

The influence of air content in waste steam on the condensation HTC value was investigated. A significant decrease in the condensation HTC value, in accordance with available literature, beginning at very low air concentrations in the steam mixture was experimentally verified. For the air concentration in the steam mixture of $1 \%$, the condensation HTC decreases according to the experiments to $62 \%$ and according to the theoretical model even to $75 \%$ of the value for the condensation of pure steam.

The values obtained from the theoretical model are slightly higher, nevertheless the experimentally obtained dependence of condensation HTC on the air content in a steam mixture has a similar curve as the dependence calculated according to the theoretical model. Any potential inaccuracy in the HTC determination on the values of the overall HTC is relatively low for this design of waste vapour condenser. The sensitivity of the shell-side HTC value to the overall HTC is more significant than the condensation HTC. When calculating the overall HTC, it is of greatest importance to precisely determine the shell-side HTC.

\section{Acknowledgement}

This research has been supported by the Grant Agency of the Czech Technical University in Prague, grant No. SGS14/183/OHK2/3T/12.

\section{References}

1. G. F. Hewitt, G. L. Shires, T. R. Bott, Process Heat Transfer (Begell House, New York, 2000)
2. J. Šesták, F. Rieger, Přenos hybnosti, tepla a hmoty (ČVUT, Praha, 2005)

3. F. P. Incropera, D. P. Dewitt, Introduction to Heat Transfer (Wiley-Academy, New York, 1996)

4. J. Havlík, T. Dlouhý, Proceedings of the 20th International Conference Engineering Mechanics 2014, 216-219 (2014) 